\title{
Cu-Pd Alloy Nanoparticles on Carbon Paper as a Self-supporting Electrode for Glucose Sensing
}

Ju Deng ${ }^{1, \#}$, Yuanyuan Li ${ }^{1, \#}$, Dongmei Deng ${ }^{1,{ }^{*}}$, Haibo $\mathrm{He}^{1}$, Xiaoxia Yan ${ }^{1}$, Jianwei

$$
\text { Zhao }^{2, *} \text {, Liqiang } \text { Luo }^{1, *}
$$

${ }^{1}$ College of Sciences, Shanghai University, Shanghai 200444, PR China

${ }^{2}$ College of Material and Textile Engineering, Key Laboratory of Yarn Materials

Forming and Composite Processing Technology, Jiaxing University, Jiaxing 314001,

Zhejiang, PR China

\# The two authors contribute equally to this work.

*Corresponding authors. E-mail addresses: dmdeng@shu.edu.cn (D. Deng); jwzhao@zjxu.edu.cn (J.Zhao); luck@shu.edu.cn (L. Luo). 


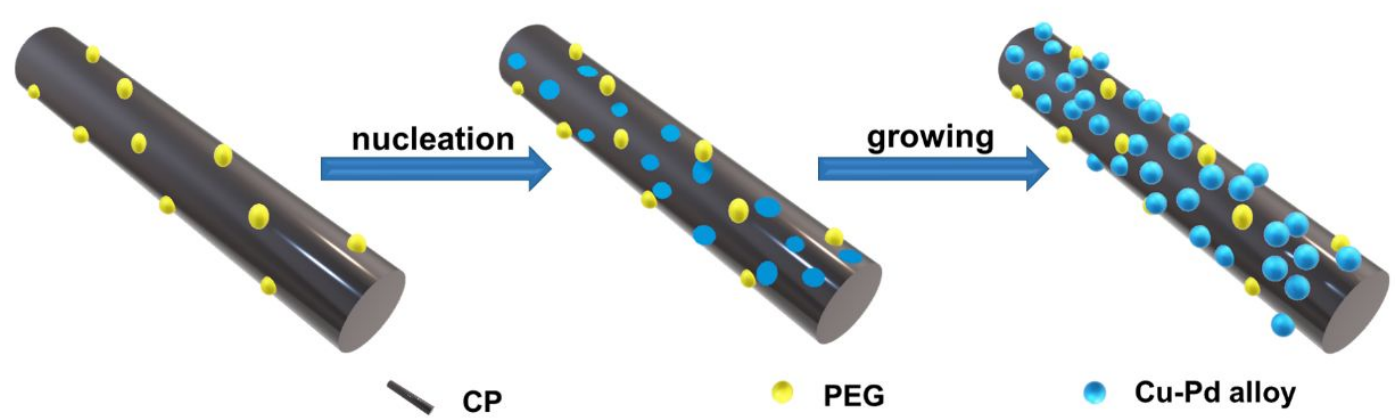

Figure S1. Schematic of mechanism of $\mathrm{Cu}-\mathrm{Pd} / \mathrm{CP}$ preparation by electrodeposition. 


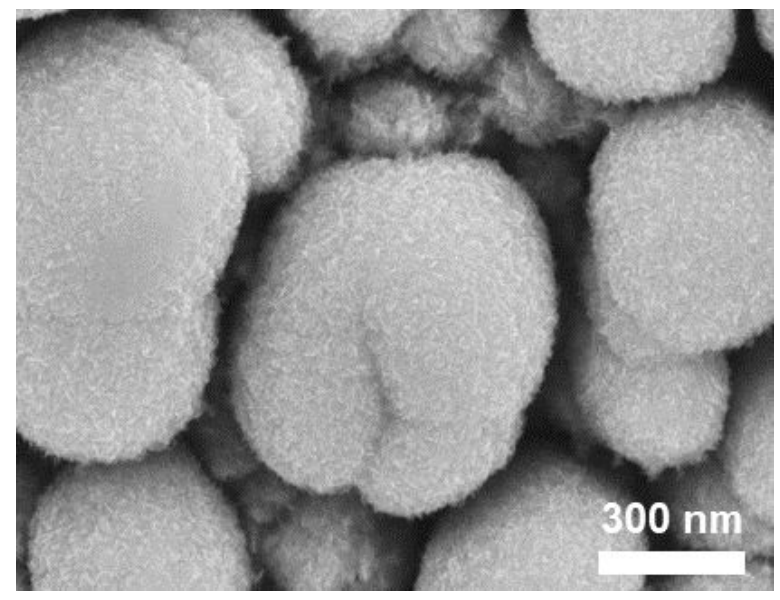

Figure S2. SEM images of $\mathrm{Cu}-\mathrm{Pd} / \mathrm{CP}$. 

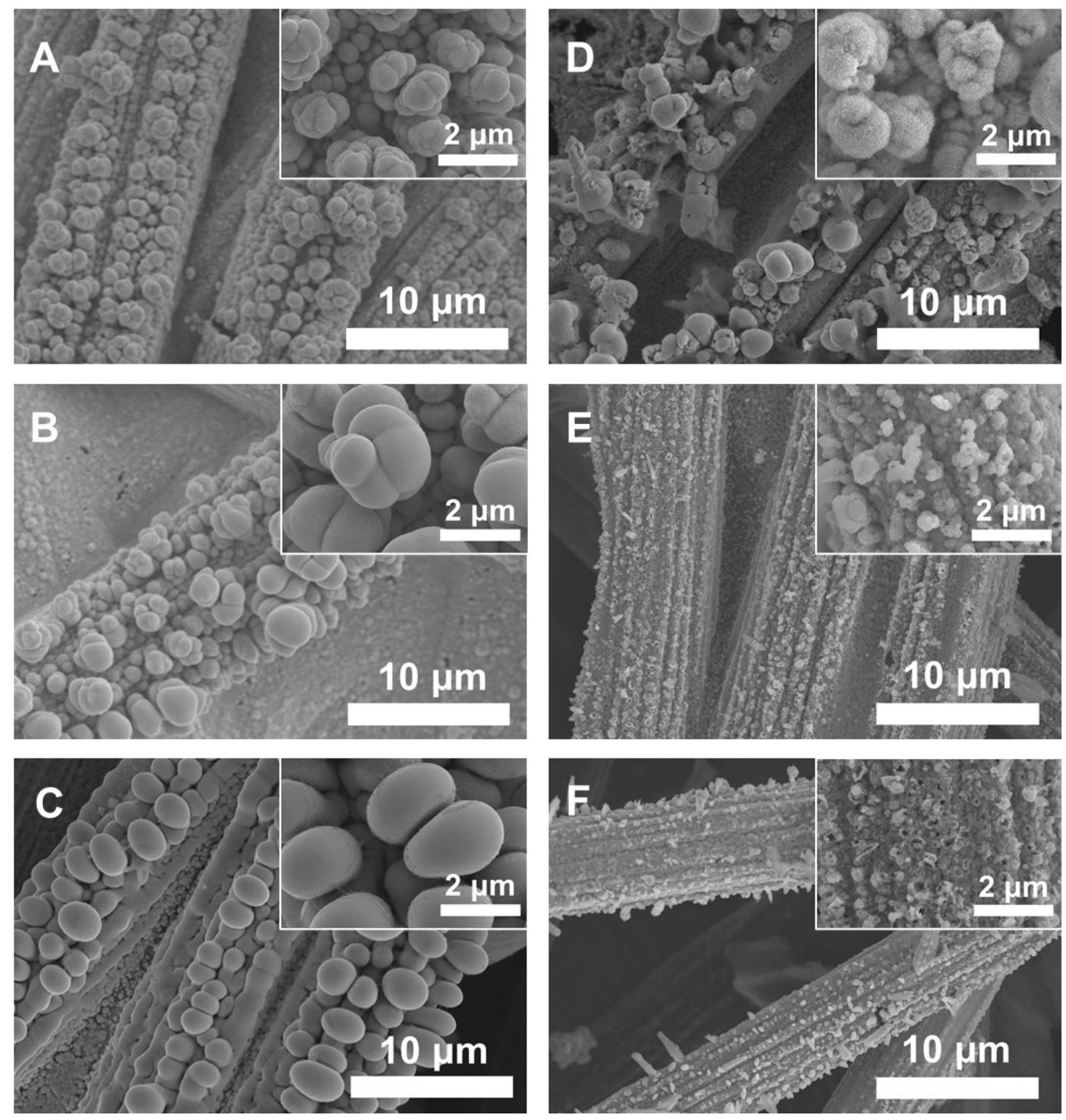

Figure S3. SEM images of Cu-Pd/CP with different concentration ratios of $\mathrm{Cu}^{2+} / \mathrm{Pd}^{2+}$ (A) 1:9, (B)

1:4, (C) 1:1, (D) 3:2, (E) 4:1 (F) 9:1. (Electrodeposition conditions: deposition voltage: $-0.5 \mathrm{~V}$; deposition time: $1 \mathrm{~h})$. 

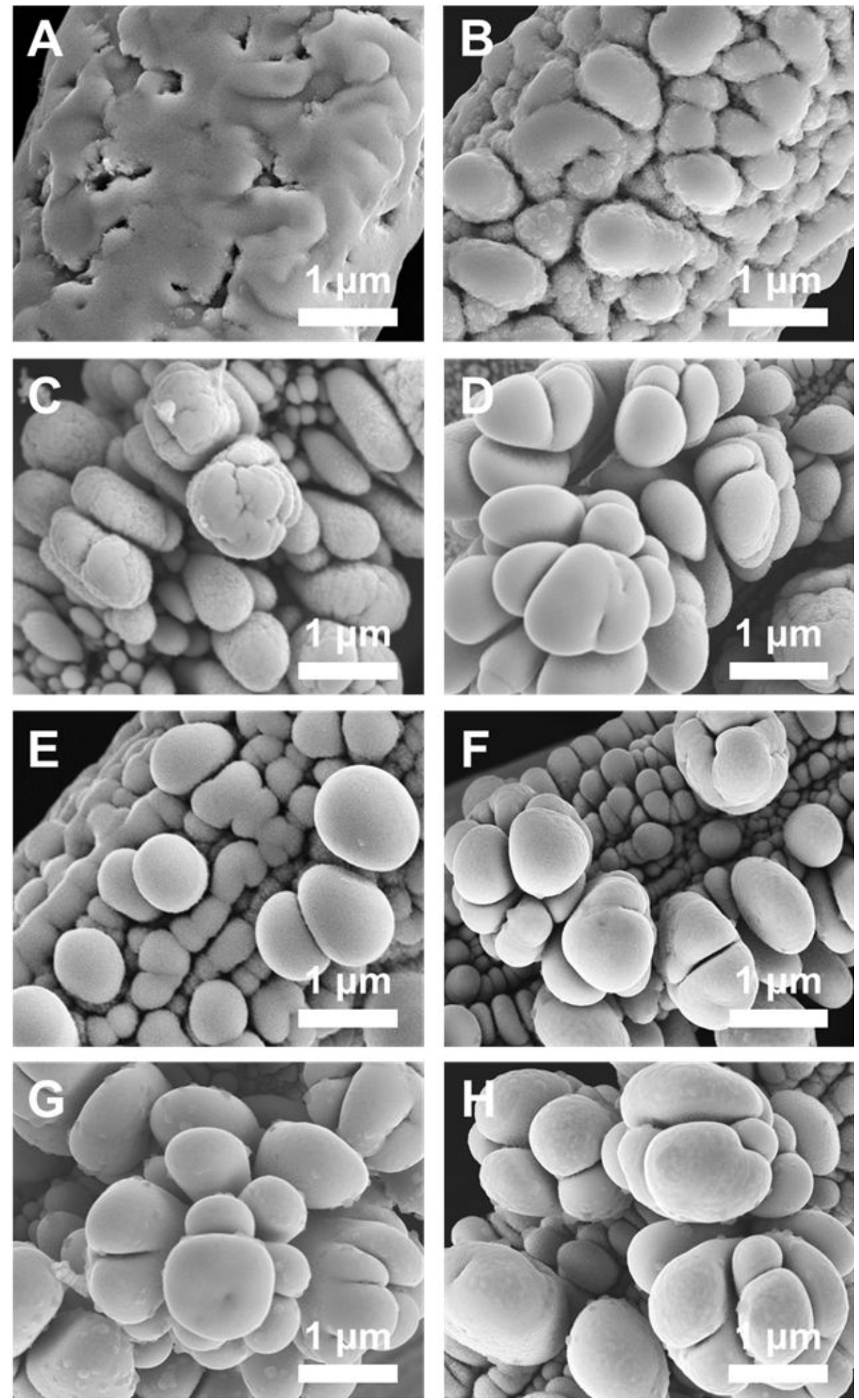

Figure S4. SEM images of $\mathrm{Cu}-\mathrm{Pd} / \mathrm{CP}$ under different deposition voltages of (A) $-0.3 \mathrm{~V}$, (B) -0.4

$\mathrm{V},(\mathrm{C})-0.6 \mathrm{~V},(\mathrm{D})-0.7 \mathrm{~V}$ and different deposition time of (E) $20 \mathrm{~min},(\mathrm{~F}) 40 \mathrm{~min},(\mathrm{G}) 80 \mathrm{~min},(\mathrm{H})$

100 min. (The concentration ratios of $\mathrm{Cu}^{2+} / \mathrm{Pd}^{2+}$ is $2: 3$ ). 

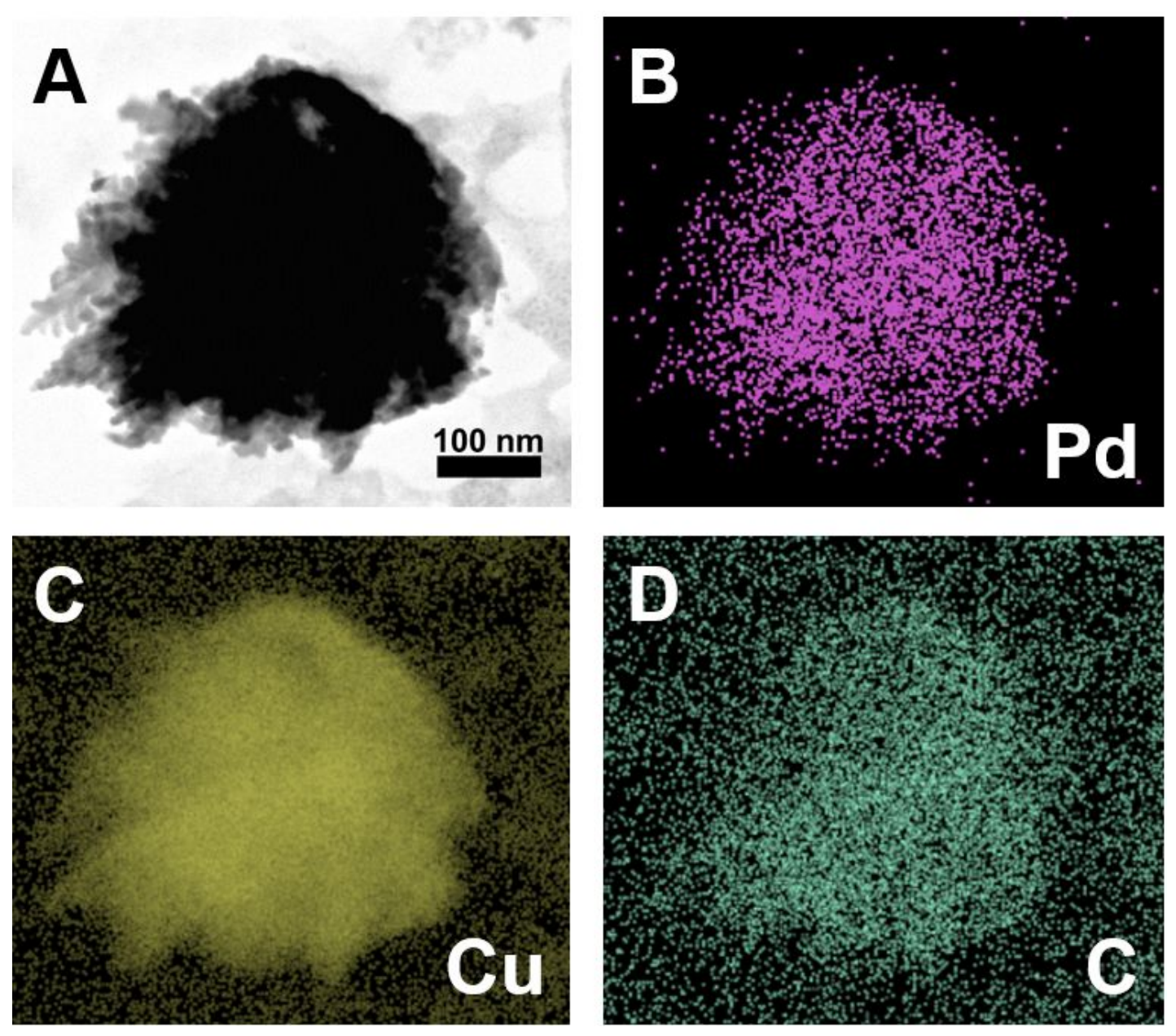

Figure S5. TEM images (A) and elemental mapping images (B, C, D) of Cu-Pd. 

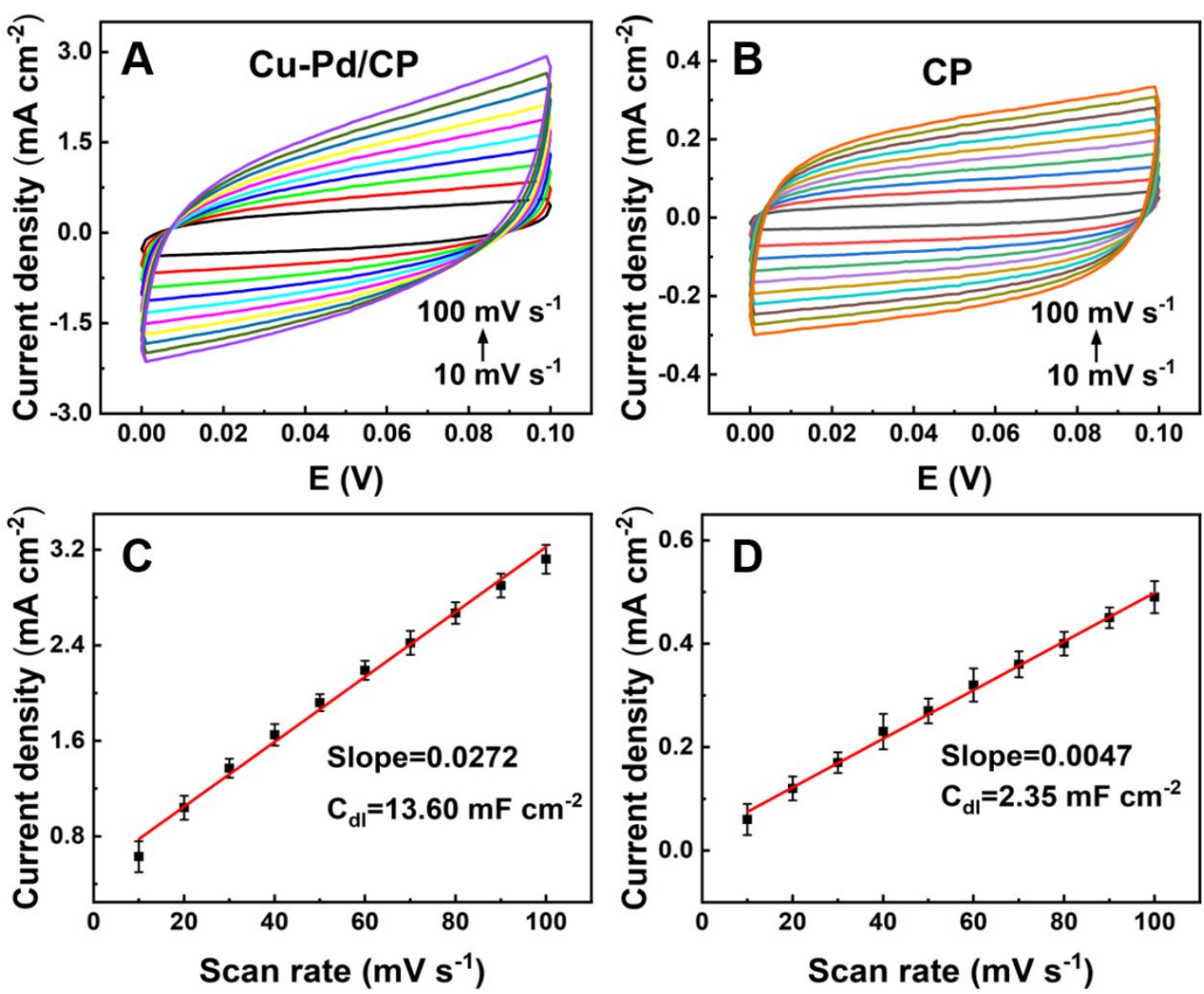

Figure S6. (A) and (B) $\mathrm{CVs}$ of $\mathrm{Cu}-\mathrm{Pd} / \mathrm{CP}$ and $\mathrm{CP}$ electrodes measured in the applied potential range from $0.00 \mathrm{~V}$ to $0.10 \mathrm{~V}$ at various scan rates. (C) and (D) The capacitive current density at $0.05 \mathrm{~V}$ as the function of scan rate for $\mathrm{Cu}-\mathrm{Pd} / \mathrm{CP}$ and $\mathrm{CP}$. 

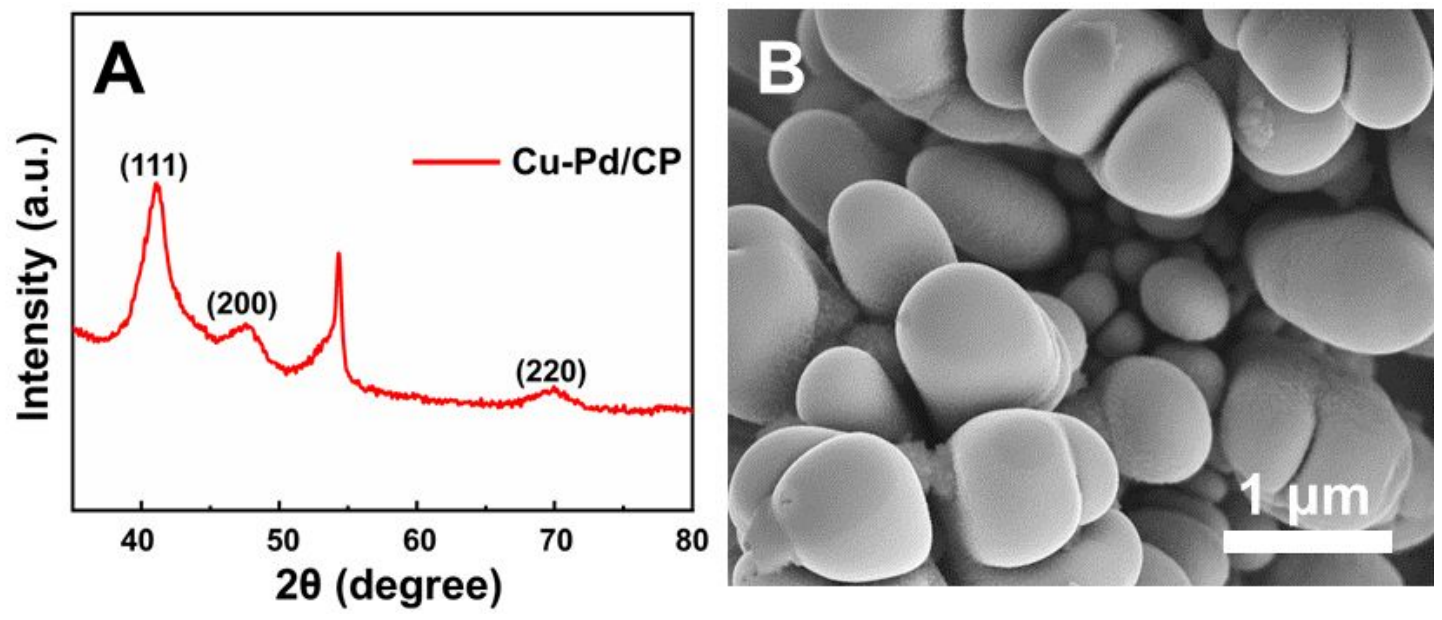

Figure S7. The XRD (A) and SEM (B) of Cu-Pd/CP after stability test. 

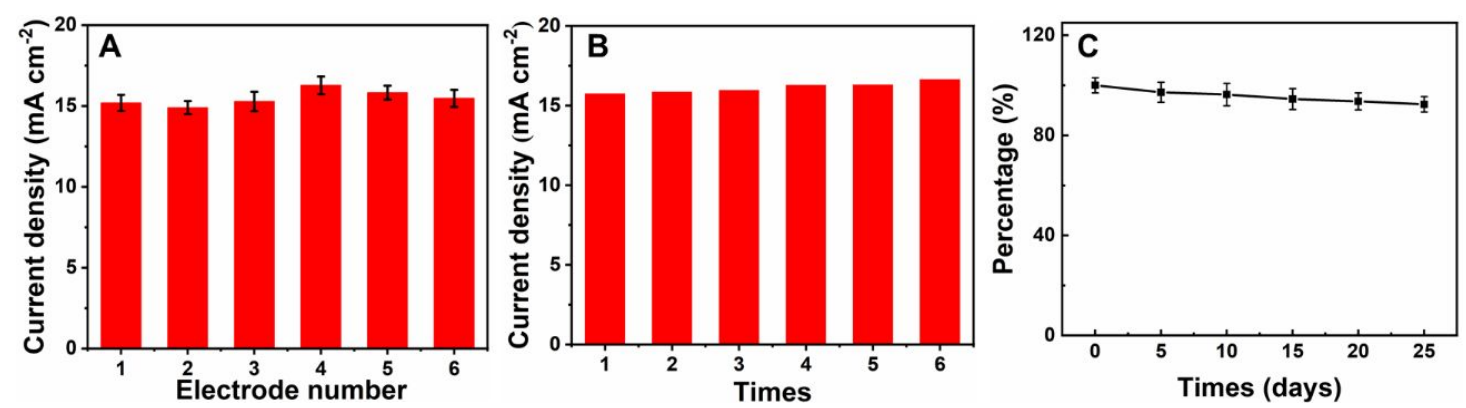

Fig. S8. (A) The reproducibility test of $\mathrm{Cu}-\mathrm{Pd} / \mathrm{CP}$. (B) The reusability test of $\mathrm{Cu}-\mathrm{Pd} / \mathrm{CP}$. (C) The stability of the $\mathrm{Cu}-\mathrm{Pd} / \mathrm{CP}$ electrode. 